\title{
It's Working: A Training Program for Foreign Teaching Assistants
}

Rosslyn M. Smith and C. Len Ainsworth

Texas Tech University

While much of the nation's attention is focused on our dependency upon foreign oil, foreign automobiles and foreign technology, members of the academy recognize a growing reliance upon another important but less well recognized resource, foreign teaching assistants (FTAs) in our colleges and universities. As fewer American citizens undertake graduate studies, many of them moving directly into high paying jobs in industry, both the number and proportion of foreign graduate students holding teaching assistantships increases.

Although accurate national statistics are difficult to obtain for all disciplines, data from the American Mathematical Society may best illustrate the current situation. In 1972-73, 1042 doctor of philosophy degrees were granted in mathematics by American universities. Seventy-eight percent of those were awarded to American citizens. In 1984-85, only 750 doctorates were awarded in mathematics, which is a decrease of more than one fourth of the former level. Of those granted in 1984-85, only 55 percent were awarded to American citizens. Since 50 percent of the graduate students pursuing mathematics degrees in the United States at the present time are foreign born, we can expect an even greater decline in the percentage of doctor of philosophy degrees granted to American born students.

This influx of foreign students to American graduate education presents both opportunities and problems to our 
institutions. On the positive side, the FTAs bring with them to the classroom a wealth of cultural information to share with their students. Their presence on American campuses helps to dispel the parochialism that sometimes characterizes our student bodies. Chandler (1985) points out that "the interpenetration of cultures through the exchange of students and scholars within an academic community is in itself a source of new knowledge and broadened perspectives" (p. 53). In addition, many FTAs have outstanding academic records and excel as researchers and students. Many also attain positions of influence in their native countries after graduation and as such serve as valuable contacts for American industry and commerce in marketing U. S. goods abroad.

The growing number of foreign TAs also causes widespread concern. Many American students resent the presence of foreigners as TAs even though the TAs have excellent knowledge of the subject matter. Some students ascribe their poor classroom performance to the limited English or unfamiliar teaching style of the FTA. The litany of complaints about FTAs, dealing primarily with their perceived inability to communicate effectively in English, has also aroused the attention of parents, university administrations, governing boards, and state legislatures. A number of states, including Missouri, Ohio, Florida, Minnesota, Kansas, Illinois, and Texas have either enacted or are considering legislation to require universities to evaluate and/or train foreign TAs before giving them teaching assignments.

\section{NATIONAL AWARENESS}

The so-called "foreign TA" problem has recently been in the national news from the Chronicle of Higher Education to Newsweek on Campus. Universities across the country are developing a variety of evaluation and training programs to address the problem. In a survey taken in 1982, Turitz (1984) identified only fifteen institutions, out of forty surveyed, with training programs for FTAs. Since the publication of Turitz' article, many more institutions have responded to the increasingly evident need to evaluate and train their FTAs. ${ }^{1}$

Perhaps the first national seminar on FTA training occurred in 1985 at a NAFSA (National Association for Foreign Student 
Affairs) sponsored three-day meeting at Georgia State University in Atlanta. Senior program administrators from a dozen institutions met to discuss a wide range of issues including curriculum, testing, and administration. In 1986, a national conference on "Institutional Responsibilities and Responses in the Employment and Education of Teaching Assistants" took place at Ohio State University. In the published readings from the conference, over one fourth of the text deals with issues pertaining specifically to FTAs (Chism, ed., 1987). In July 1987 the University of Wyoming, with partial funding from NAFSA, hosted their second annual institute for program directors and instructors in the field of FTA testing and training. The first week of the institute addressed the needs of beginners in the field; the second week was an advanced workshop. On the regional level, Texas Tech University and NAFSA co-sponsored a two-day workshop for universities in Texas and Louisiana on the "Design and Implementation of FTA Training Programs" in May 1987. Finally, preconference workshops, panels, and papers relating to FTAs are now prominent in the programs of the national and regional conferences of TESOL (Teachers of English to Speakers of Other Languages), NAFSA, and other professional organizations.

\section{PROGRAM DESCRIPTION ${ }^{2}$}

Texas Tech University began a training and evaluation program for foreign TAs in 1980. This program differs from many others in several respects. First, the program is comparatively old and well established on campus. Second, the program did not arise out of a crisis situation, but rather evolved over several years from a summer pilot project with eight participants (Smith, 1982), to a year-round effort involving an average of thirty prospective FTAs annually. Finally, the teaching staff represents several departments on campus rather than being entirely from an ESL program or an instructional resource center, such as the Harvard program (Sarkisian, 1986).

\section{Goals}

The goals of the training program at TTU address the special needs of foreign TAs and the students they teach. These 
goals are to:

1. orient students to the U.S., to the local environment, and to the university;

2. Acquaint participants with cultural variables that may affect them in the classroom;

3. develop understanding of the role of teachers in American higher education classrooms in terms of expectations, relationships with students, and responsibilities;

4. provide intensive training in English pronunciation and intonation and practice in instructional strategies and classroom communication skills;

5. provide follow-up assistance during the student's first semester of teaching through observation and individualized feedback;

6. provide reevaluation and training for those with unsatisfactory performance;

7. provide a forum for foreign TAs to discuss their classroom teaching problems and explore solutions.

\section{Admission}

Students enter the training program for prospective foreign TAs either by departmental and graduate school requirement or by departmental recommendation. International students receive teaching assistantships contingent upon successful completion of the TA workshop. This university requirement ensures that no non-native English speaker teaches without appropriate testing and training. Self-supporting international students or those employed as research assistants often wish to participate and may attend the summer workshop on a space-available basis.

\section{Pre-Screening}

Some departments use an informal pre-screening process before offering assistantships to students from overseas or from out-of-town. Students applying to the departments of math or chemistry submit a five to ten minute audiocassette tape of a lecture on a topic in their field. When the tapes arrive, the graduate advisor of the department and the director of the training program assess the student's potential in the classroom 
and his or her likelihood of successfully completing the workshop. A holistic measure of overall comprehensibility is the primary criterion used in this assessment.

\section{Testing}

When the students arrive on campus for the three week summer workshop portion of the training program, they take the Michigan battery, a series of placement/diagnostic English tests developed by the University of Michigan. The battery includes a 100-item multiple-choice test of grammar, vocabulary, and reading comprehension; a 30-minute impromptu composition; and a 90-item multiple-choice, taped listening comprehension test. At the end of the workshop, the listening comprehension test is readministered to measure any gain in listening comprehension ability. At the end of the second week, students also take the SPEAK (Speaking Proficiency English Assessment Kit) test, published by the Educational Testing Service. The SPEAK score supplements the daily evaluations the instructors make of each student's speaking ability.

Students may also take the Myers-Briggs Type Indicator (the MBTI), a psychological typing instrument based on the work of psychiatrist Carl Jung and used to identify learning styles. Students attend group or individual feedback sessions directed by a faculty member who is an authority on the Myers-Briggs. The MBTI makes the FTAs aware of their own preferences and sensitizes them to the varieties of learning styles they will encounter in the classroom.

\section{Curriculum}

In the summer workshop, students engage in a demanding schedule of classes and activities. There are four main components of the program: cross-cultural orientation, classroom communication, English, and a practicum. ${ }^{3}$

Cultural orientation. This unit lasts for 10-14 hours and includes (1) the phases of transitional adjustment, (2) definition of the terms culture, perception, communication, and values, (3) comparison of values using charts, film, case studies, and small group work, and (4) awareness of and expectations for change. 
Classroom communication. This component runs from 22-26 contact hours. Topics covered include the definition of communication, intercultural adjustment, nonverbal communication, classroom communication, and classroom administration. Instructors give particular emphasis to teacher image, credibility, types of presentations, first impressions, handling conflict, and presentational skills.

English. The English component consists of 16-18 hours of pronunciation and intonation practice and evaluation. Students work on vocabulary in their field, reading aloud, consonant sounds weak and strong vowels, rhythm and sentence stress, some idiomatic expressions, and building listening comprehension skills.

Practicum. The practicum includes 16-18 hours of work integrating the skills being learned and making presentations which are videotaped. Students view the first taped presentation in class; they view the other two presentations individually with the instructor, at which time they receive personalized feedback. The topics of the taped presentations include (1) defining a term or describing a geometric shape or figure, (2) describing a process, and (3) simulating a classroom lecture or presentation including using visual aids and fielding questions. Other discussions focus on what makes a person a good teacher, the parts of a class (rapport building time, attention getter, content, and closings), general discourse signals, interactive discourse, handling questions, active listening, and question formation. Students also view and discuss brief videotaped segments of actual classroom or lab presentations by instructors at U.S. Universities.

\section{Materials Used}

Gary Althen's booklet Manual for Foreign Teaching Assistants has been used since its publication in 1981 as a basis for discussion. Students also receive a variety of locally developed materials to use in preparing talks, practicing pronunciation, and other workshop activities. Other texts consulted are Alison Lanier, Living in the U. S. A.; Hoopes and Ventura, eds., Intercultural Sourcebook: Cross-Cultural Training Methodologies; Edward Stewart, American Cultural Patterns: A CrossCultural Perspective, and Weeks, Petersen, and Brislin, eds., 
A Manual of Structured Experiences for Cross-Cultural Learning. There is no comprehensive FTA training text per se available at this time; however, Byrd, Constantinides, and Pennington have written a text that is in press and that should be a valuable asset to instructors. ${ }^{4}$

\section{ADMINISTRATION AND STAFF}

The TA training program involves several administrative units. The office of the Vice President for Academic Affairs and Research (VPAAR) authorizes and funds the program. Each year this office provides money for maintenance and operation, for the appointment of instructors, and for the housing costs incurred. The university realizes that requiring a three week training session prior to the fall semester could place an undue financial burden on students from out-of-town or overseas. Therefore this group of students receives campus room and board. Participants already in the Lubbock area provide their own housing and food.

Since all TAs are graduate students, the Graduate School assists in the identification of students who should participate. The Graduate School also enforces the requirements of attendance and satisfactory completion of the program.

Many other administrative offices and individuals cooperate in the implementation of the program. These include the deans of the participating colleges, the graduate advisors, the housing and budget offices, student services, and international programs.

The director of the English for Speakers of Other Languages (ESOL) Program coordinates the training program and is responsible for most of the administrative details relating to the workshop. Specific duties include notifying departments of the workshop, making housing and scheduling arrangements, managing the budget, setting up the curriculum, locating and training teaching staff, fielding any questions about participation, and providing the pre-workshop information to participants. In addition to teaching a section of the program, the director also compiles the evaluations and makes a final decision on who passes, submits all final reports, and reevaluates later in the year students who did not pass.

The Office of International Programs plays an important role in the training program. They mail the students university 
prearrival information, provide early processing on campus, assist in getting the students settled in campus housing, and provide orientation to the campus and community. The director of the Office of International Programs also teaches the cultural orientation section of the summer program.

Instructors for the classroom communication portion of the training come from the Department of Speech Communication. Both regular faculty and advanced graduate students have instructed during the summer. For the past three years an ESL instructor has also assisted the director in the English training of the students during the summer workshop.

\section{RESULTS AND FOLLOW-UP}

At the end of the workshop each instructor in the program submits a written evaluation of the participants to the director. In most cases departmental representatives view the final videotaped presentations of their students. This departmental review is extremely important since it gives the departments an opportunity to participate in the evaluation process and to have a better understanding of the training. The director compiles all the evaluations and places students into one of three categories. should not teach at this time, may teach with close supervision, may teach with routine supervision. In the past three years the percentage of students who successfully complete the workshop has been over 60 percent.

Students who do not successfully complete the workshop may pursue several alternatives. Some receive or continue on research assistantships, while other work as graders or technicians. Some enroll in ESL conversation or grammar and composition courses. Students who wish to be reevaluated at the end of the Fall or Spring semesters may present another talk in their field at a special evaluation session. The graduate advisor and one or more faculty members from the department attend, as well as the director of the training program and sometimes one or two American students. If a prospective TA has made sufficient progress since the last evaluation, he or she becomes eligible to receive a teaching assignment.

Departmental graduate advisors receive a list of students and their final rating, usually within one day of the end of the summer workshop. This notification includes any recommended 
or required coursework in English. Departments may then offer assistantships to students and arrange other means of support for those who fail. Advisors also receive a detailed report of each student's English problems and progress within a few days. The Vice President for Academic Affairs and Research receives a summary report with copies to the Graduate School and all participating departments.

In 1984 the university began a follow-up course in the fall semester for those TAs who go through the summer workshop and subsequently teach. The course provides additional instruction in teaching skills and English pronunciation and intonation, and is a forum for students to ask questions or raise issues that concern them about their own teaching situations. The format of this course changed in 1986 to include classroom observations, additional videotaping, and tutorial sessions.

Since the training program began, departments report greater satisfaction with, and fewer complaints about the English proficiency of their foreign TAs. In general, graduate advisors and department chairs are enthusiastic about the results. Cooperating faculty develop sensitivity to the problems and potential of the teaching assistants. The foreign students who participate, although initially skeptical and somewhat resentful at having to attend, report high levels of satisfaction at the content and quality of the program. One indication of the success of the program is that in 1986, a foreign TA won the university outstanding TA award, and other FTAs are beginning to win departmental teaching awards.

\section{IN SUMMARY}

The evaluation and training program at Texas Tech is not a panacea for the problems inherent in using foreign TAs. It has, nevertheless, improved the quality of instruction and greatly reduced the number of student complaints. It is an example of cooperative approaches toward solution of a widespread problem. In the future we will be exploring ways to increase departmental participation in the program and to individualize the follow-up to a greater extent. We also hope to sensitize American students to the problems faced by the foreign TA, as well as heighten their awareness of the opportunities for cultural enrichment that the TAs bring to the classroom. 


\section{REFERENCES}

Althen, G. (1981). Manual for foreign teaching assistants. Iowa City, Iowa: The University of Iowa.

Byrd, P., Constantinides, J., and Pennington, M. (forthcoming). A manual for foreign TAs. Macmillan.

Chandler, A. (1985). Foreign students and government policy; Britain, France, and Germany. Washington, D. C.: American Council on Education.

Chism, N. Ed. (1987). Institutional responsibilities and responses in the employment and education of teaching assistants: Readings from a national conference. Columbus, Ohio: The Ohio State University Center for Teaching Excellence.

Hoopes, S. and Ventura, P. Eds. (1979). Intercultural sourcebook: Crosscultural training methodologies. Chicago: Intercultural Press, Inc.

Lanier, A. (1981). Living in the U.S. A. Yarmouth, Maine: Intercultural Press, Inc.

Sarkisian, E. (1986). Learning to teach in an American classroom: Narrowing the culture and communication gap for foreign teaching assistants. In M. Svinicki, J. Kurfiss, and J. Stone (Eds.). To improve the academy. A joint publication of The Professional \& Organizational Development Network in Higher Education and The National Council for Staff, Program and Organizational Development.

Smith, R. M. (1982). An intensive summer workshop for foreign teaching assistants: A pilot project. TESOL Newsletter, 16(3), 31.

Stewart, E. C. (1972). American cultural patterns. Chicago: Intercultural Press, Inc.

Weeks, W. H., Petersen, P. B., and Brislin, R.W.(Eds.).(1985). A manual of structured experiences for cross-cultural learning. Yarmouth, Maine: Intercultural Press, Inc.

\section{NOTES}

1. See Janet Constantinides (1987). "The 'foreign TA problem' -an update," NAFSA Newsletter 38(5), 3-6, for an overview of this issue, including resources available for developing and conducting training programs.

2. An abbreviated program description that focuses on curricular issues appears as "Foreign TA training at Texas Tech," (1987). In N. Chism (ed.). Institutional responsibilities and responses in the employment and education of teaching assistants: Readings from a national conference. Columbus, Ohio: Ohio State University Center for Teaching Excellence.

3. For a discussion of design factors to consider in program development, see Janet Constantinides, "Designing a Training Program 
for International Teaching Assistants." (1987). In N. Chism (ed.), Institutional responsibilities and responses in the employment and education of teaching assistants: Readings from a national conference. Columbus, Ohio: Ohio State University Center for Teaching Excellence.

4. Readers interested in other materials may wish to contact Janet Constantinides, Department of English, University of Wyoming, for a catalog of materials from the Clearinghouse on International TA Training Programs. 